\title{
Use of statins is associated with a lower prevalence of generalised osteoarthritis
}

Recent reports, from The Netherlands ${ }^{1}$ and the UK, ${ }^{2}$ suggest that statins have a modifying role in osteoarthritis $(\mathrm{OA})$ using different outcome definitions, specifically radiographic OA in the Rotterdam cohort and general practitioner diagnosis from a national database in the UK study. On the other hand, a large longitudinal study from the USA found that statin use was not associated with improvements in knee pain, function or structural progression over a 4-year period. ${ }^{3}$ A separate US longitudinal study in elderly women found that statin use may be associated with an increased risk of developing incident radiographic hip OA. ${ }^{4}$ The discrepancies between published studies on statins and OA may be due to methodological factors as has been discussed elsewhere. ${ }^{5}$

Studies of generalised OA suggest the potential role of systemic processes in disease pathogenesis. ${ }^{6}$ It has been hypothesised, based on evidence from in vitro studies, that a dysfunction in lipid metabolism may play a role in the pathogenesis of OA. ${ }^{7}$

It is therefore possible that lipid dysregulation may be involved more in generalised polyarticular OA than in single large joint OA. Generalised OA (GOA) refers to the involvement of at least three joints, or a group of joints, for example, the interphalangeal (IP) joints. The nodal type of GOA, characterised by Heberden's and Bouchard's nodes predominates in women and associates with underlying radiographic IP OA. ${ }^{8}$ There is no agreed consensus definition for generalised OA, but the presence of IP nodes has been shown to result in a different profile of risk factors for both hip and knee OA. ${ }^{9}$

In order to test if statin use is associated with generalised nodal OA, we used data from the Genetics of OA and Lifestyle (GOAL) study, a large case-control study involving clinically severe OA cases, with full radiographic assessment, recruited from secondary care. ${ }^{8}$ We focused on the following eight outcomes: (1) nodal OA defined as Heberden's or Bouchard's nodes affecting two or more rays of both hands; (2) knee OA defined as a Kellgren-Lawrence $(\mathrm{K} / \mathrm{L})$ score $\geq 2$ at the tibiofemoral compartment of either knee excluding hip OA; (3) radiographic hip OA defined as a $\mathrm{K} / \mathrm{L} \geq 2$ at either hip excluding knee OA; (4) hip and knee OA pelvis $\mathrm{K} / \mathrm{L} \geq 2$ at either hip and tibiofemoral $\geq 2$ at either knee; (5) generalised knee OA defined as knee OA in addition to nodal status excluding hip OA; (6) generalised hip OA defined as hip OA in addition to nodal status excluding knee OA; (7) generalised hip and knee OA; (8) any GOA (the sum of 5, 6 and 7 above). Details on X-rays and patient recruitment have been reported elsewhere. ${ }^{9}$ The descriptive characteristics of study participants are shown in table 1 .

After adjustment for confounders we find no evidence for an association between nodal OA, hip OA or knee OA and use of statins (table 2). However, use of statins is associated with a lower prevalence of the GOA phenotype. This association 


\begin{tabular}{|c|c|c|c|c|}
\hline \multirow[b]{2}{*}{ Characteristic } & \multicolumn{4}{|c|}{ Statin use* } \\
\hline & No & & Yes & \\
\hline $\mathrm{n}$ & 2510 & & 661 & \\
\hline Years on statin medication & 0 & & 4.28 & (3.39) \\
\hline Age years mean (SD) & 65.96 & $(8.10)$ & 68.8 & $(6.52)$ \\
\hline $\mathrm{BMI} \mathrm{kg} / \mathrm{m}^{2}$ mean (SD) & 29.10 & $(5.27)$ & 29.92 & $(5.19)$ \\
\hline Years with joint pain mean (SD)† & 8.49 & $(9.46)$ & 8.55 & $(9.88)$ \\
\hline$F(n=1537) \%(n)$ & $51.3 \%$ & $(n=1288)$ & $37.7 \%$ & $(n=249)$ \\
\hline Cardiovascular disease $(n=1679) \%(n) \ddagger$ & $43.1 \%$ & $(n=1082)$ & $90.3 \%$ & $(n=597)$ \\
\hline Medication for pain $(n=1767) \%(n)$ & $54.9 \%$ & $(n=1378)$ & $58.8 \%$ & $(n=389)$ \\
\hline Ever-smoked: ex-smokers $(n=1487)$ and current smokers $(n=429) \%(n)$ & $58.0 \%$ & $(n=1457)$ & $69.4 \%$ & $(n=459)$ \\
\hline Controls $(n=805) \%(n)$ & $26.7 \%$ & $(n=669)$ & $20.6 \%$ & $(n=136)$ \\
\hline Nodal OA $(n=106) \%(n) \S$ & $3.3 \%$ & $(n=83)$ & $3.5 \%$ & $(n=23)$ \\
\hline Knee OA $(n=729) \%(n) \emptyset$ & $21.8 \%$ & $(n=546)$ & $27.7 \%$ & $(n=183)$ \\
\hline Hip OA (n=499) \% (n)ף & $15.9 \%$ & $(n=399)$ & $15.1 \%$ & $(n=100)$ \\
\hline Hip and knee OA $(n=427) \%(n) \uparrow$ & $12.7 \%$ & $(n=318)$ & $16.5 \%$ & $(n=109)$ \\
\hline Generalised knee OA: nodal+knee $(n=238)$ & $7.5 \%$ & $(n=188)$ & $7.6 \%$ & $(n=50)$ \\
\hline Generalised hip OA: nodal+hip $(n=142)$ & $4.7 \%$ & $(n=118)$ & $3.6 \%$ & $(n=24)$ \\
\hline Generalised hip and knee OA: nodal+hip and knee $(n=225)$ & $7.5 \%$ & $(n=189)$ & $5.4 \%$ & $(n=36)$ \\
\hline
\end{tabular}

${ }^{*}$ Study participants underwent a home visit ${ }^{9}$ and the research nurse reviewed medications and repeat prescriptions from participants. Participants were classified as being on statin medication if they were taking any of the following medications: pravastatin, rosuvastatin, simvastatin, atorvastatin or fluvastatin. No information on dose was available.

†For patients with only knee OA (nodal or not) this is the years with knee pain; for patients with hip OA, the years with hip pain; for patients with both knee and hip OA, this is the largest of years with hip or knee pain; controls are not included, for asymptomatic cases it is 0 .

$\ddagger$ Comorbidities were evaluated by nurse-applied questionnaire. A participant is considered to have cardiovascular disease if they replied yes to the question 'have you been diagnosed by your general practitioner or a specialist to have heart disease or hypertension'.

§The presence of Heberden's and Bouchard's nodes was assessed by a nurse. The nodal phenotype was defined as Heberden's and/or Bouchard's nodes that affected at least two rays of each hand.

THip OA was defined as Kellgren-Lawrence at the pelvis $(K / L) \geq 2)$ knee $O A$ cases $(K / L \geq 2)=1617$ controls.

BMI, Body Mass Index; OA, osteoarthritis.

Table 2 Association between statin use and prevalence of OA phenotypes in the GOAL study

\begin{tabular}{|c|c|c|c|c|c|c|}
\hline & \multicolumn{3}{|c|}{ Adjusted for age, sex, BMI } & \multicolumn{3}{|c|}{ Adjusted for additional covariates } \\
\hline & OR* & $95 \% \mathrm{Cl}$ & p Value & ORt & $95 \% \mathrm{Cl}$ & p Value \\
\hline Nodal OA & 1.11 & (0.59 to 2.09$)$ & 0.74 & 1.04 & (0.53 to 2.05$)$ & 0.91 \\
\hline Hip OA & 0.98 & (0.70 to 1.38$)$ & 0.93 & 1.00 & (0.68 to 1.48$)$ & 0.99 \\
\hline Knee OA & 1.32 & (0.99 to 1.75$)$ & 0.06 & 1.27 & (0.91 to 1.77$)$ & 0.15 \\
\hline Knee and hip OA & 1.04 & (0.75 to 1.43$)$ & 0.83 & 0.92 & (0.63 to 1.34$)$ & 0.66 \\
\hline Generalised hip OA & 0.85 & (0.52 to 1.38$)$ & 0.51 & 0.80 & (0.47 to 1.35$)$ & 0.40 \\
\hline Generalised knee OA & 0.91 & (0.59 to 1.41$)$ & 0.67 & 0.79 & (0.46 to 1.35$)$ & 0.40 \\
\hline Generalised knee and hip $0 A$ & 0.66 & (0.42 to 1.01$)$ & 0.06 & 0.63 & (0.38 to 1.04$)$ & 0.07 \\
\hline All generalised $O A$ & 0.75 & (0.59 to 0.94$)$ & 0.012 & $0.76 \ddagger$ & (0.59 to 0.97$)$ & 0.028 \\
\hline
\end{tabular}

${ }^{*} \mathrm{OR}=\mathrm{OR}$ for association between statin use and $\mathrm{OA}$. Association was assessed by logistic regression, with hip OA, knee OA or generalised OA being the outcome variables, statin use (yes/no) the independent variable, and including age, sex and Body Mass Index (BMI), as covariates.

tFurther adjustment for a diagnosis of hypertenstion or any form of cardiovascular comorbidity, smoking (never smoked=0, ex-smoker=1, current smoker=2) and use of pain medication was also performed.

$\ddagger$ Additional adjustment for stroke, kidney disease, type 2 diabetes, and years with pain at the target joint $0 R=0.77(0.60$ to 0.99$) p<0.048$.

GOAL, genetics of OA and lifestyle; OA, osteoarthritis.

Bold font indicates a statistically significant $(p<0.05)$ result.

remains statistically significant after further adjustment for a diagnosis of various comorbidities (table 2).

The present study has a number of limitations: its crosssectional nature, a hospital-based case control design, and the lack of statin dose information. Nonetheless, our data provide further evidence supporting that statin use may affect OA although in our case only a specific OA phenotype (ie, generalised nodal OA). Given the lack of structure-modifying drugs, ${ }^{10}$ it would be much welcome news if statins were proved to reduce OA risk or progression even if this was only on a subset of patients. Further studies primarily designed to address this question are warranted.
A M Valdes, ${ }^{1}$ W Zhang, ${ }^{1}$ K Muir, ${ }^{2}$ R A Maciewicz, ${ }^{3}$ S Doherty, ${ }^{1}$ M Doherty ${ }^{1}$

${ }^{1}$ Academic Rheumatology, University of Nottingham, Clinical Sciences Bld, Nottingham City Hospital, Nottingham, UK

${ }^{2}$ Institute of Population Health, University of Manchester, Oxford Road, Manchester UK

${ }^{3}$ Respiratory, Inflammation, Autoimmunity iMed, AstraZeneca AB, Mölndal, Sweden

Correspondence to Ana M Valdes, Academic Rheumatology, Clinical Sciences Building, Nottingham City Hospital Hucknall Road, Nottingham, NG5 1PB, UK; ana.valdes@nottingham.ac.uk

Contributors All authors contributed to the study design, data interpretation and the final manuscript. AMV analysed and interpreted the data and prepared the manuscript. 
Funding Supported by a EULAR project grant to AMV (grant 108239), AstraZeneca UK funded the GOAL study sample and data collection.

Competing interests None.

Ethics approval The Nottingham City Hospital and North Nottinghamshire Research Ethics Committees.

Provenance and peer review Not commissioned; externally peer reviewed.

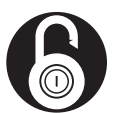

\section{OPEN ACCESS}

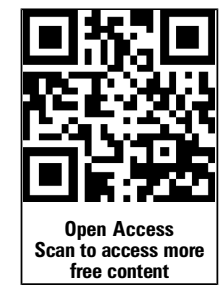

Open Access This is an Open Access article distributed in accordance with the Creative Commons Attribution Non Commercial (CC BY-NC 3.0) license, which permits others to distribute, remix, adapt, build upon this work non-commercially, and license their derivative works on different terms, provided the original work is properly cited and the use is non-commercial. See: http://creativecommons.org/ licenses/by-nc/3.0/

To cite Valdes AM, Zhang W, Muir K, et al. Ann Rheum Dis 2014;73:943-945.

Received 1 August 2013

Revised 17 October 2013

Accepted 2 December 2013

Published Online First 17 December 2013

Ann Rheum Dis 2014;73:943-945. doi:10.1136/annrheumdis-2013-204382

\section{REFERENCES}

1 Clockaerts S, Van Osch GJ, Bastiaansen-Jenniskens YM, et al. Statin use is associated with reduced incidence and progression of knee osteoarthritis in the Rotterdam study. Ann Rheum Dis 2012;71:642-7.

2 Kadam UT, Blagojevic M, Belcher J. Statin use and clinical osteoarthritis in the general population: a longitudinal study. J Gen Intern Med 2013;28:943-9.
3 Riddle DL, Moxley G, Dumenci L. Associations between statin use and changes in pain, function and structural progression: a longitudinal study of persons with knee osteoarthritis. Ann Rheum Dis 2013;72:196-203.

4 Beattie MS, Lane NE, Hung YY, et al. Association of statin use and development and progression of hip osteoarthritis in elderly women. J Rheumatol 2005;32:106-10

5 Clockaerts S, Van Osch GJ, Bierma-Zeinstra SM. Comment on 'associations between statin use and changes in pain, function and structural progression: a longitudinal study of persons with knee osteoarthritis'. Ann Rheum Dis 2013;72:e9.

6 Cooper C, Egger P, Coggon D, et al. Generalized osteoarthritis in women: pattern of joint involvement and approaches to definition for epidemiological studies. J Rheumatol 1996:23:1938-42.

7 Conaghan PG, Vanharanta H, Dieppe PA. Is progressive osteoarthritis an atheromatous vascular disease? Ann Rheum Dis 2005:64:1539-41.

8 Thaper A, Zhang W, Wright G, et al. Relationship between Heberden's nodes and the underlying radiographic change. Ann Rheum Dis 2005:64:1214-16.

9 Valdes AM, McWilliams D, Arden NK, et al. Involvement of different risk factors in clinically severe large joint osteoarthritis according to the presence of hand interphalangeal nodes. Arthritis Rheum 2010;62:2688-95.

10 Conaghan PG. The effects of statins on osteoarthritis structural progression: another glimpse of the Holy Grail? Ann Rheum Dis 2012;71:633-4. 